\title{
The Application of Pragmatic Strategies in International Trade Disputes Xiulian Liu ${ }^{1}$ and Liyang Gong ${ }^{2}$

\author{
School of Foreign Languages, Jianghan University, Wuhan 430056, China \\ 1liuxiulian1000@sina.com, ${ }^{2} 2360491251 @ q q . c o m$
}

\begin{abstract}
Keywords: International trade dispute; Maximum relevance; Optimal relevance; Institutional power; Psychological motivation
\end{abstract}

\begin{abstract}
Pragmatic strategies play an important role in international dispute settlement. In 2016, the victory of China in thirteen anti-dumping lawsuits against the United States was greatly contributed by the use of pragmatic strategies. A subtle use of them cannot only settle the international dispute in a short time, but also maintain long-term cooperation in the future. Maximum relevance and optimal relevance help listeners get sufficient contextual effects by adequate efforts, sustaining the communication in a smooth way. Institutional power and psychological motivation of adaptation helps speaker control the topic and strengthen his advantageous position.
\end{abstract}

\section{Introduction}

China has witnessed an increasingly further development with other countries as a result of globalization. In recent years, the United States has become one of the top interactive countries with China. However, what follows a soaring trade volume between the two countries is trade dispute.

To better cope with the trade disputes and maintain a healthy and harmonious relationship with trading partner, China has formulated a special way, under the basic rules of WTO, to negotiate with other countries. In this way, how to negotiate for the best result becomes very important.

On December 3, 2013, China filed a lawsuit against thirteen anti-dumping cases of America, involving mechanical and electrical products, light industrial products and minerals[1]. Having experienced indictment, direct negotiation and third-party conciliation etc., China finally won the lawsuits in 2016. The reason why China has won the lawsuit, except the unambiguous evidence that China has collected, is that Chinese delegates have eloquent pragmatic skills.

International trade dispute comes from unfair benefit distribution especially when a hegemonism country holds a view that the balance of international benefit allocation has been broken. Nothing weights more importance than benefits, and in this condition, a defendant country is privileged to plead for itself. When it comes to pleading, pragmatic strategies, to a certain degree, guarantee half the success of an international trade dispute settlement.

In a lawsuit, statistics make evidence powerful and speaking skill makes oneself easily understood. Pragmatic strategies can achieve double effect with only half effort by persuading others in a more reasonable way and quell dissatisfaction as soon as possible. As it is widely acknowledged that "the dispute settlement procedure of WTO is quite complicated and inefficient for it usually takes at least one year to deal with a dispute. Even an error in speaking or a slow response of a defendant will make listener hold different subjective feelings, stirring unnecessary argumentation. Therefore, rational use of pragmatic strategies enables defenders to avoid such disadvantages on the spot and grasp the key points so as to reach the perfect resolution of disputes.

The success of an international trade dispute will facilitate further development to a nation's economy. More importantly, the outcome of the relevant verdict will together constitute a "precedent" and will help China become initiative in the future while encountering similar problems in international trade disputes. When the next trade dispute arrives, the former success provides reference for successors and also prevents similarly consequent incidents, thus reducing external friction.

In a foreign trade, "the long-term interest is a matter that both parties attach great importance to"'[2]. Polite expressions, appropriate and graceful language can weaken embarrassment and avoid 
direct conflict, providing an opportunity for further cooperation. In a dispute settlement, the most important issue is to eliminate each party's doubts and protect their own interests, leaving room for both sides in the course of the defense so as to facilitate a long-term cooperation.

\section{Relevant Theories of Pragmatics}

Pragmatics is the study of who the speaker of the sentence is, who the hearer is, when and where it is used. In this regard, this paper emphasizes relevance and adaptation as its point of observation.

Relevance. Sperber and Wilson propose relevance theory which was related to communication and cognition[3]. It is actually a kind of "cognitive psychology theory" based on the general cognitive view to study human communication and discourse comprehension. Relevance theory studies discourse comprehension from the perspective of cognitive psychology, believing that the human mind evolves in a highly efficient direction and their attention and cognitive resources tend to deal with those associated information automatically, and discursive understanding involves reasoning and computation of psychological representations. In other words, "the processing information of human mind is driven by relevance which copes with existing information so as to construct a new discourse character"'[4]. Sperber and Wilson acknowledge the fuzziness of the concept of association, believing that different users have different usages, and that even one user may have different usages at different times. Therefore, to understand the relevance, one must first understand what is "contextual effect" because the latter is the necessary and sufficient condition for the former one. Below are the detailed characters of "contextual effect":1) Cognitive effects combined with current contextual assumptions produce contextual meaning. 2) Cognitive effects reinforce current contextual assumptions (provide more evidence for contextual assumptions). 3) Conflict occurs between cognitive effects and current contextual assumptions (provide strong evidence against contextual assumptions) [3].

This means when the other condition is the same, the greater the contextual effect is, the stronger the relevance is. The pragmatic meaning can be easily understood instantly by the listener, the relevance power of the sentence will be very powerful. Generally speaking, human cognition is consistent with the maximum relevance, therefore, the optimal relevance is expected in the communication. To obtain the optimal relevance, both of the following two conditions must be achieved: 1) The contextual effect of a speaker is able to arouse the listener's attention; 2) Listeners make inferential efforts to obtain contextual effects[3].

When the discourse has enough relevance and it is worthy to be processed, especially when the discourse has the maximum relevance that the speaker is willing to speak it out, at this moment, the discourse has the optimal relevance. To comprehend the discourse more accurately, what a listener tries to pursue intentionally is the optimal or the maximum contextual effect. In general, the optimal or the maximum contextual effect is the effect that a listener could not obtain from another discourse or context at the time. The quality of the contextual effect depends on the listener's cognition of the existing contextual assumptions.

Adaptation. Adaptation is deeply related to the way of choosing strategies and how an appropriate discourse is produced. In describing and explaining the use of language, four aspects of information should be paid attention to. They are: "1.contextual correlates of adaptability; 2.structural objects of adaptability; 3.dynamics of adaptability; 4.salience of the adaptation processes". [5]

The meaning of communication is generated in the negotiation process. The cognitive environment of both parties in communication is constantly changing in the communication process. Language communication can be regarded as the dynamic process of the questioner's choice of language in order to achieve specific communicative purposes and to adapt to the changing communication environment. The selection process mainly includes the choice of language forms and strategies. In this process of dynamic communication, the questioner can adapt to the context successfully and achieve his own communicative goals by conforming to different communicative objects and constantly selecting verbal forms and strategies. "In studying the linguistic choices of 
language users, adaptation theory considers contextual factors like linguistic, physical, social and psychological etc. and can better reflect the complexity and ingenuity of linguistic choices during the court trial'"[6].

In court, the questioner chooses different strategies according to the changing psychological motivation, thus achieving different communicative purposes (such as overthrowing cooperation or overthrowing false confessions).

\section{Application of Pragmatic Strategies in International Trade Disputes}

Pragmatic strategies help listeners get sufficient contextual effects and help speakers control the topic in the discourse. By a subtle use of relevance and adaptation, Chinese delegates sustain their positions in dispute settlement.

Application of Relevance. As has been mentioned in part II, maximum relevance is related to one's cognitive ability while optimal relevance refers to one's ability in discourse. Thus in court settlement of international trade dispute, maximum relevance means some specific information that are widely acknowledged by everyone and nobody needs to try very hard to comprehend the meaning, while optimal relevance means people need to distinguish the useful information from various words so as to fully understand the subtle and artful meaning behind its appearance. The use of these two pragmatic strategies will help speaker confirm himself clearly and convince more people in court.

Maximum Relevance. Maximum Relevance will be reached by understanding the discourse with least effort, which means every one can understand it as soon as he hears it. listener's attention and cognitive resource tend to deal with the associated information automatically. Relevant knowledge and background knowledge will help him fully understand the meaning. No one can ensure that speaker's meaning can be completely understood and accepted by others, thus he must make sure that what he says are accurate and brief and can best convey proper meaning. In this regard, one needs to know the widely accepted abbreviation and terminology. The following two examples will approve that.

- "The United states acted inconsistently with Article 2.4.2 of the Anti-dumping Agreement in three challenged determinations of the United States Department of Commerce(USDOC), because in each of these determinations:

- The USDOC used the WA-T methodology without having properly met the first condition of Article 2.4.2, second sentence. Specifically: the USDOC used the statistical tools of its own choices in an arbitrary and biased manner...".[7]

In this long sentence, China has made a complaint against the United States of making unfair illustrations on both American laws and WTO rules. "Article 2.4.2" has been mentioned twice in this sentence, which means this rules is known by everyone in court and everyone knows the content of this article thus no more explanation is needed to further illustrate its meaning behind. In order to avoid misunderstanding and ambiguity when expressing submissions, China has chosen to itemize the statements though some of them have not been mentioned in this paper. In this way, the opposite party can instantly know the complaint of China at the first sight of the submission.

According to what has been mentioned before, maximum relevance is used here as all the people can understand its meaning with their existing knowledge of WTO rules. Since all the delegates of three parties and judges from WTO are equipped with the knowledge of WTO rules and they are familiar with all the Articles that have been or will be mentioned in court, they can understand the basic meaning very easily and deal with those associated information automatically.

Optimal Relevance. Explicit stimulation is consistent with the ability and preference of the speaker, so it has the maximum relevance. Based on the above assumptions, if a discourse has the optimal relevance, it must first have the maximum relevance. Having a good command of basic background knowledge of the discourse, the listener then is able to get the contextual effect by his reasoning and computation ability.

Following the example in maximum relevance, the phrase "arbitrary and biased manner" seems to be more vague in the sentence for people would not know how arbitrary and how biased America is when illustrating anti-dumping laws. Different people will hold different views towards the phrase 
and it is only when more illustrations are given will people better understand it. Someone may think that the rules of USDOC and WTO are essentially unfair and the U.S. government just follows the rules. Others may hold the view that it is America government that does not treat both two laws in a balanced way and they only choose the rules that are beneficial to themselves no matter whether they break fairness or not. In this regard, people will analyze the meaning of it and after some efficient inference, people will get the information that they are willing to get. In the example that is mentioned, "arbitrary and biased manner" means America has double standard towards anti-dumping rules. In terms of trade volume, the surplus of China ranks first in all the trade companions of the United States. To change the adverse situation, USDOC will crack down on Chinese companies on the basis of an arbitrary and biased illustration on anti-dumping laws, even the law they use is contrary to theirs. In this case, optimal relevance is used with the aim of making people get sufficient contextual effect.

The following three sentences will better prove the role that optimal relevance plays in international dispute settlement:

- "a)...Article 6.1 of the Anti-Dumping Agreement, because the USDOC did not give notice of the information required and did not provide ample opportunity for certain interested parties to present, in writing, all evidence they considered to be relevant.

- b)The USDOC failed to properly undertake a reasoned and selective evaluation in order to find the best facts available and failed to provide a reasoned and adequate explanation of how it had exercised special circumspection and selected the best information available".[7] In sentence a), USDOC fails to pay attention to the specific information. At first sight of the phrase "the information required", listener may be confused of its meaning. But those who are involved in the settlement can easily understand it because the United States does have acted inconsistently in some Articles and it refuses to admit the mistake by quibbling that it does not pay much attention on the related rules of WTO. In this case, China indirectly points it out and leaves some space for the United States to think of it. Moreover, at the end of the sentence, "all evidence they considered to be relevant" means the United States does not provide sufficient evidence and the evidence it provides is not relevant to the complaint that China has put forward. In this case, the judges need to further think the inner meaning of China's submission and with sufficient efforts, they can easily get the contextual effect. In sentence b), phrases like "reasoned and selective evaluation" , "the best facts available" are all so vague in meaning that listener cannot get their contextual effect at once and needs to further think of it. By stating the adjectives, China wants to inform the United States of the biased punishment they have done on Chinese entrepreneurs. Based on the definition of optimal relevance that is mentioned before, it is worthwhile for a listener to make some efforts so as to deal with the inner meaning of the discourse and the submission of China is consistent with the ability and preference of the speaker. By analyzing the words of Chinese delegates, the United States will know the fact that China has used a euphemism expression to inform them of the unfair illustration on anti-dumping lawsuits.

Based on above analysis, if a discourse has the optimal relevance, it must have the maximum relevance. Optimal relevance will not be achieved without a basic acknowledgement of maximum relevance. The quality of the contextual effect depends on the listener's cognition of the existing contextual assumptions. In this way, optimal relevance is achieved when the listener needs to use his knowledge to achieve sufficient contextual effects.

Application of Adaptation. Institutional power and psychological motivation are two important strategies of adaptation in a courtroom. Institutional power helps speaker control the topic and avoid adverse situation while psychological motivation helps speaker emphasize the key point of his utterance.

Institutional Power of Adaptation. In most cases, defendants will feel extremely nervous because the final judgment is firmly correlated with their future and even their lives. They may be afraid that if they acknowledge the accusation, they have to undertake more punishment. To evade the crucial charge, they will sometimes remain vague on speaking or even refuse to utter any word. In this regard, the quizzer will use some pragmatic strategies to control the defendants. 
Using Coercive Words. Coercive words appear frequently in both daily life and a solemn court. Since coercive words can show one's determined mind and a strong will to illustrate the facts, they are often widely used in a dispute settlement. However, in the studied text, threatening information is obvious though coercive words are not apparently shown in the lines. The following example will prove that.

- "a) Finally, China requests that the Appellate Body find that an investigating authority has an obligation to examine these qualitative factors on its own initiative as part of the applicable legal standard under Article 2.4.2..

- .b) Accordingly, China requests that the Appellate Body declare the statement made in footnote of the Panel Report to be moot and of no legal effect". [8]

The word "requests" from sentence a) shows Chinese delegates' determined attitude of appealing the United Stated to firmly obey the rules of WTO and USDOC. Moreover, words like "has an obligation" means China has a high expectation on the United States, who can strictly obey the rules and implement the fair and just principle when examining the qualitative factors. In sentence b), "moot and of no legal effect" once again indicates that China holds a firm view that the United States has made an error in the report and China stoutly believes that the United States has an unfair and biased standard toward Chinese companies. Of the two coercive word mentioned above, word like "requests" can be regarded as a symbol which shows directly tough determination while "moot and no legal effect" can only vaguely indicate one's dissatisfaction.

Statistics show that the United States has adopted biased measure toward Chinese companies. China has to take some effective measures especially when the opposite party sternly refuses to admit their errors. By coercive words, Chinese delegates show their firm attitude of the United States in biased anti-dumping lawsuits, thus giving pressure to the opposite party.

Controlling Topic. Topic controlling is one of the ways in which questioners conform to achieve institutional power. Topic controlling is an important strategy to control the speaker. When the respondent deviates from the topic, the questioner can limit the topic by interrupting and transferring the topic. In order to make the jury have a clear picture of the case, those who ask questions often pay great attention to the consistency of the speech. Sometimes, however, the questioner may suddenly change the subject to comply with the institutional power, thereby preventing the speaker of offering adverse information about himself to the judges.

- "China submits that the USDOC acted inconsistently with the pattern clause of Article 2.4.2 by applying the Nails test without confirming whether this assumption was correct, or in other words, without verifying that the export price data in the three challenged investigations were indeed normally distributed or at least single peaked and symmetric.

- - The United States does not dispute that the USDCO did not test the export price date to confirm whether it was normally distributed or single-picked and symmetric. However, the United States asserts that the pattern clause of Article 2.4.2 imposes no obligation on an investigation authority to examine how export prices are distributed in a given investigation"[7].

In the dialogue mentioned above, the contention of China is the Nails test depended on the assumption that the examined export price date was either normally distributed or singled-peaked and symmetric is not based on any statement by the USDOC. To be consistent in the speech, Chinese delegates directly point out that the United states does not make clear distinctions among "normally distributed, singled-peaked and symmetric". Because the distinctions of these there standards are so important that they can decide whether China has broken Nails test or not. To enhance the advantageous position in the mentioned discourse, Chinese delegates limit the topic by illustrating the errors of the United States. The response of the American delegates is quite subtle because on the one hand, they admit that they do not follow the investigation as China has put forward; on the other hand, they try to evade the mistake and claim faintly that there is no obligation to do so.

Questioner's choice of language can help him achieve specific communicative purposes. As a questioner, China has an advantageous position and is bound to win the complaint. Topic 
controlling helps China strengthen its power in the discourse and prevents the United States of deviating from the topic. In this process, China has a good command of topic controlling and the explanation of the United States is so faint that it has no choice but to avoid the topic.

Psychological Motivation of Adaptation. During a dispute settlement, psychological motivation will help speakers control listeners' mood and make them frankly utter the truth.

Repeating Relevant Information. Subject to the limitation of discipline, the questioner often cannot confirm whether the present person truly understands the answer made by the respondent or not and whether he truly understands the intention of the questioner or not. So the questioner will use the third turn or follow-up language (immediately after the answer of the dialogue) to repeat the relevant content so that he can emphasize a certain important information, together with the aim of appealing all members. In everyday conversation, unobtrusiveness of repetition of the previous speaker's voice means objection to its correctness, and to remind the opposite party to reconsider or make some relevant changes.

- "China appeals the Panel's error in interpreting an applying the first of the two pre-conditions under Article 2.4.2, second sentence, of the Anti-Dumping Agreement for having recourse to the exceptional weighted average-to-transaction("W-T") comparison methodology(the "pattern clause'). The pattern clause requires that there be "a pattern of export prices which differ significantly among different purchasers, regions or time periods" (a "relevant pricing pattern"). Specifically, China appeals errors in the manner...".[8]

In the mentioned paragraph, Chinese delegates first clarify the errors in interpreting anti-dumping rules, and repeat the pattern clause that is illustrated by the opposite party. Finally, China shows its own resolutions to the errors. Along this logic line, listener can easily get the aim of the repetition of "pattern clause". Being aware that the United States will not admit the biased judgment they have made before, Chinese delegates use repetition as a way of emphasis. By informing the United States of the fact again and again, China shows a determined attitude of changing the situation. As Chinese delegates doubt the fairness of America's illustration on Article 2.4.2, they first cite what the United States has mentioned and find the contradiction it has made. Following the logic, solutions will be easily accepted by the judges. In this regard, the third turn plays a vital important role in the mentioned paragraph. It makes the logic line much clearer and enhances the stringency by pointing out contradictions of the opposite party.

Reformulating Information. During the court trial, the questioner often uses some legal language in order to establish his authority. However, sometimes in order to promote cooperation, the questioner will use verbal language to repeat the questions that have been asked, which often makes the views better understood by all the people and gives pressure to the opposite side, forcing them to utter their views more clearly.

- "China asserts that, statistically speaking, when a given data set is normally distributed or single-peaked and symmetric, 50\% of the data points will fall below the mean. Further, when data are normally distributed, only $15.87 \%$ of the data points will fall one standard deviation below the mean. In contrast, when data are not normally distribute...".[7]

The sentence, more specifically speaking, is a detailed illustration of "normally distributed or single-picked and symmetric". Following the example of Topic Controlling, China gives a definite description of the three important standards. As is mentioned in Topic Controlling, "normally distributed or single-picked and symmetric" is so important that they can decide who the truth teller is. In order to give pressure to the judges and the opposite side, China uses specific data to convince all the members of the complete difference standards. In the example of Topic Controlling, China points out "the USDOC acted inconsistently with the pattern clause of Article 2.4.2 by applying the Nails test without confirming whether this assumption was correct". Compared to the specific date in the present sentence, the formal one only gives a vague description and fails to further illustrate the distinctions. To make up the unspecific illustration, China adds more detailed date and the United States cannot avoid the problem but to face the question this time. Strictly restrained by the discipline, delegates cannot fully explain the details at first and can only use some legal terminology like "without confirming whether they were correct" to briefly show the view. 
The use of reformulation in the sentence makes the views of China more powerful and more persuasive while forcing the opposite party to admit the error they have made. Reformulation helps speaker emphasize what he has mentioned before, thus forcing the opposite side to answer the question more clearly. Based on a meticulous consideration, China has chosen a more specific way to illustrate the vague information by using data and definitive descriptions.

Psychological motivation affects and restricts language user's choice when implementing a specific speech or act. As one can easily be affected by incisive questions, his Psychological activity is changed accordingly in different situations.

\section{Conclusion}

After a rough calculation, the use of maximum relevance ranks first which appears at the beginning of a delegate's statement every time for its direct expression of facts and is easily understood by all the people. Optimal relevance, though it is not widely used in the dialogue, shows a vital importance in conveying euphemistic and subtle inner-meaning of different discourse and gives the opposite party a shocking and anxious psychological hint. The use of coercive words appears as often as maximum relevance, with the aim of showing dissatisfaction and giving pressure to the opposite side. Topic controlling is rarely used as its most important effect is to avoid adverse statement of the opposite party. However, with adequate preparation and sufficient evidence, China is sure of success. Repetition and Reformulation is frequently used in dispute settlement because by repeating and paraphrasing the words from others or themselves, one can easily emphasize what he wants to point out, thus making his views much clearer. Generally speaking, maximum relevance and optimal relevance will help speaker confirm himself clearly and convince more people of the complaint in court. Coercive words and topic controlling may make mighty party more powerful and weak party more faint. Repetition and reformulation, though quite similar, help the speaker emphasize his view. All in all, the pragmatic strategies mentioned above play different roles in the communication and make significant contributions to efficiency and persuasive power of international trade disputes.

\section{References}

[1] W. D. Wang. "China Wins the Lawsuits: WTO Declares13 Anti-dumping Lawsuits of U.S. Illegal. https://wallstreetcn.com/articles/268538. 2016

[2] Y. Zuo. "Pragmatic Strategies in Marketing Activities". Jiangsu Commercial Forum3(2011): 112-113.

[3] D.Sperber \& D.R. Wilson,: Communication and Cognition. Harvard University Press, Cambridge. 1986.

[4] Z. R. He. New Development in Pragmatics: Relevance, Adaptation and Memetics. Shanghai: Shanghai Educational Publishing House, 2007

[5] Z. R. He \& Y. P. Ran. New Edition of Pragmatics. Beijing: Peking University Press, 2009.

[6] Y. P. Ran \& X. J. Zhang. An Overview of Pragmatics. Beijing: Higher Education Press, 2007.

[7] WTO: "United States - Certain Methodologies and Their Application to Anti-dumping Proceedings Involving China, Report of The Panel(WT/DS471/R)". 2016. https://www.wto.org/english/tratop_e/dispu_e/471r_e.pdf

[8] WTO: "United States - Certain Methodologies and Their Application to Anti-dumping Proceedings Involving China(WT/DS471/8)". https://www.wto.org/english/news_e/news16_e/ds471ap1_18nov16_e.html 